\title{
Collaboration between the EFSA GMO Panel and national EU competent authorities for the environmental risk assessment of GM crop cultivation applications
}

\author{
K. Lheureux, S. Mestdagh, and Y. Devos \\ European Food Safety Authority (EFSA), Parma, Italy \\ Correspondence to: Karine Lheureux, European Food Safety Authority (EFSA), Largo N. Palli 5/A, I- 43100 Parma, Italy, \\ E-mail: karine.Iheureux@efsa.europa.eu
}

Regulation (EC) No. 1829/2003 (Articles 6.3.c and 18.3.c) concerning GM food and feed requires that, "in case of GMOs to be used as seeds or other plant-propagating material falling within the scope of the Regulation, EFSA is under the obligation to ask a national competent authority (CA) designated under Directive 2001/18/EC to carry out the environmental safety assessment (ERA) of such GMOs". Up to date, EFSA has received 12 cultivation applications under the GM food and feed Regulation (EC) (representing 15\% of all applications received under the Regulation) and is currently collaborating with Belgium, Germany, Spain, the Netherlands and the United Kingdom on cultivation applications ${ }^{1}$.

Since 2004, EFSA has put in place a common procedure for each cultivation application. As soon as EFSA receives a new application including the scope of cultivation, EFSA launches a "call for expression of interest" to all national CAs which then have 3 weeks to express their interest. The most suitable CA candidate is nominated on the basis of its experience in conducting ERA and drafting national risk assessment reports, experience with the crop/trait in the application, and ability to conduct the task in the allocated time. If no national CA expresses interest in the launched call, EFSA follows a second step and, following the recommendations provided by the European Commission consulted on that issue, would formally nominate the Member State where the application was originally submitted.

During the evaluation, the nominated CA has 4 months (phase 1) to carry out the ERA and submit its report to EFSA.
Following submission, the GMO Panel has 2 months (phase 2) to finalise its scientific opinion. The GMO Panel concludes on the ERA based on the information provided by the applicant, available scientific literature, the report from the nominated CA and comments raised by all MS during the 3-month consultation period (Articles 6.4 and 18.4 of the GM food and feed Regulation). During phase 1, 3 meetings comprising an introductory, intermediate and a final meeting are organised between experts from the national CA, members of the GMO Panel and EFSA scientists, in order to allow exchange of views on the scientific information provided by the applicant and lack of scientific information. At any stage, both the CA and GMO Panel can require additional information from the applicant, which would then extend the foreseen time frame of 6 months.

Up to now, the GMO Panel has received 4 ERA reports from CAs. In these 4 cases, the GMO Panel is in agreement with the scientific issues identified and discussed by the different MS. However, MS's interpretations on how to deal with some issues differ in some cases. The GMO Panel is currently in phase 2 for these 4 applications and has not yet finalised its ERA and scientific opinions.

The GMO Panel considers the collaboration with the national CA of MS is extremely useful and very constructive and is looking forward to the participation of additional MS in future calls for expression of interest.

To access this journal online:

http://www.birkhauser.ch/JVL 